\title{
The Geography of the Great Recession*
}

\author{
Alessandra Fogli \\ Università Bocconi, University of Minnesota, Minneapolis FED, IGIER and CEPR \\ Enoch Hill \\ University of Minnesota and Minneapolis FED \\ Fabrizio Perri \\ Università Bocconi, University of Minnesota, Minneapolis FED, IGIER, NBER and CEPR
}

September 2012

\begin{abstract}
This paper documents, using county level data, some geographical features of the US business cycle over the past 30 years, with particular focus on the Great Recession. It shows that county level unemployment rates are spatially dispersed and spatially correlated, and documents how these characteristics evolve during recessions. It then shows that some of these features of county data can be generated by a model which includes simple channels of transmission of economic conditions from a county to its neighbors. The model suggests that these local channels are quantitatively important for the amplification/muting of aggregate shocks.
\end{abstract}

JEL Classification: E32, R12

Keywords: Business Cycles, Economic Geography

${ }^{*}$ We thank our discussants, Jonas Fisher, Karen Helene Ulltveit-Moe, the editors Francesco Giavazzi and Ken West, as well as participants to the 2012 ISOM conference in Oslo for excellent comments and suggestions. We also thank David Van Riper and Mike Mommsen for valuable help with geographical data. Finally thanks to Zillow research for giving us access to their data-set of county level housing prices. All remaining errors are our own. 


\section{Introduction}

This paper has two main objectives. The first is to document, using county level data, some geographical features of the US business cycle over the past 30 years, with particular focus on the Great Recession. The second is to argue that the geographical dimension of business cycles is important in explaining the transmission and amplification of economic conditions across time and across space. Using monthly data on US unemployment rates at the county level, we analyze the geographical onset and spreading of recessions over the last three decades. We show that at the onset of the recession, unemployment rises sharply in a few counties, not necessarily geographically close. This implies that at the start of a recession the spatial dispersion of unemployment rates typically increases, and that the spatial correlation (clustering) of unemployment typically falls. As the recession progresses we find that counties around those in which unemployment increased initially are more likely to be "infected" with high unemployment, generating clusters of counties characterized by high unemployment rates. This in turn drives up spatial correlation. As the recession progresses further, the increase in unemployment becomes more generalized across counties. As a consequence, the spatial dispersion in unemployment rates across counties decreases and the spatial correlation (clustering) also stabilizes. These patterns, resembling an inverted $\mathrm{U}$ for the spatial dispersion and a V shape for the spatial correlation, are observed for most recessions in our sample. These patterns also persist if one controls for cyclical movement in local unemployment that are attributable to similarity in industrial composition for counties that are geographically close.

The patterns suggest that geographic transmission might play an important role in amplifying and propagating an aggregate shock. To explore this hypothesis more precisely, in the second part of the paper we develop a very simple and mechanical model of business cycle across time and space. The engine of business cycle is an aggregate shock that hits all counties. Importantly though we allow the same shock to have different consequences on different counties, depending on county specific conditions. For example, a county which has a strong local productivity conditions might not suffer an increase in unemployment, even when hit by a large negative aggregate shock. Or, a county which has most of its employment concentrated in a very weak firm, might suffer a very large increase in unemployment even in response to a small aggregate shock.

In this environment we introduce two channels of local geographic connection between counties. The first is that local conditions of neighboring counties might be contemporaneously correlated. For example, if demand is high in a given county because of high productivity and high income 
in that county, that will keep unemployment low in that county and, through local trade, in neighboring counties. The second channel is the effect of unemployment in a given county today on future unemployment in neighboring counties through migration and commuting.

We then calibrate this model using several moments of aggregate employment and of county level unemployment. We go on to show that the calibrated version of the model can generate patterns of spatial correlation and spatial dispersion which are broadly consistent with the patterns mentioned above. Finally, we use the model to assess the importance of local geographic connections for aggregate unemployment dynamics and find that they can play a quantitatively large role in either amplifying or muting aggregate shocks. In particular we find that when the economy is hit by small aggregate shocks, local connections tend to mute the effect of the shock. When instead the economy is hit by large aggregate shocks, local connections tend to magnify aggregate unemployment fluctuations. To give some illustrative numbers, we consider a counterfactual experiment in which we cut in half the calibrated strength of local connections; in this case unemployment in the 2001 recession (a small one) would have increased by over $3 \%$, as opposed to an actual increase of $2 \%$. On the other hand, with weaker local connections, the increase in unemployment in the Great Recession would have been lower by half a percent, and unemployment would have fallen more rapidly. The intuition for this result is that when local connections are stronger, county idiosyncratic conditions tend to average out and to be more concentrated around the mean. Having the conditions of all counties more concentrated means there are less "weak" counties but there are also less "strong" counties. If a small aggregate shock hits the economy, a shock that induces unemployment only in "weak" counties, then more local connections, by reducing the fraction of weak counties, make the economy more resilient to the shock. However, if the economy is hit by a large shock, which only "strong" counties can endure without experiencing increasing unemployment, then local connections, by reducing the number of "strong" counties, make the economy more vulnerable to the shock. ${ }^{1}$

In terms of literature this paper integrates two different lines of research: the macro literature on business cycles, that analyzes the factors leading to recessions and their consequences on macro aggregates, and the regional/urban literature, which analyzes the spatial properties of economic phenomena and focuses on explaining differences in local outcomes. Standard business cycle models ignore spatial heterogeneity, and standard spatial models ignore macroeconomic dynamics over the cycle. In this work we argue that establishing a connection between these two lines of research is fruitful.

\footnotetext{
${ }^{1}$ For a similar mechanism in a different context see Philippon (2003)
} 
Regarding the regional/urban literature, the papers that are more related to our work are those which focus on the spatial structure of regional unemployment disparities and analyze the channels of interdependence among regions. This literature (see e.g. Molho 1995, Petrongolo and Wasmer 1999, Burgess and Profit 2001, Overman and Puga 2002, Elhorst 2009, Niebuhr 2003) shows the existence of spatial dependence in unemployment rates, and explores the possible linkages between neighboring regions that can give rise to the observed degree of interdependence.

Regions are tightly linked by migration, commuting and interregional trade. These types of spatial interaction are exposed to the frictional effects of distance, possibly causing the spatial dependence of regional labor market conditions. Typically the papers in this literature estimate a significant degree of spatial correlation among unemployment rates in regional labor markets and analyze the role of these different channels in determining it.

For Europe, Overman and Puga 2002 conclude that the unemployment rates of European regions are much closer to the rates of adjacent regions than to the average rate of other regions within the same EU country. The spatial concentrations of areas with similar skill composition or sectoral specialization are not found to be the primary cause of this spatial association. The analysis of Niebuhr 2003 also points to a significant spatial dependence in unemployment rates across European regions. Moreover, the evolution of regional unemployment is also marked by spatial effects. The results suggest that the change in regional unemployment between 1986 and 2000 was associated with an increasing concentration of high unemployment rates in spatial clusters. Using data on unemployment rates at the Travel-to-Work Areas (TTWAs) level for England, Scotland and Wales over the period 1985-2003, Patacchini and Zenou (2007) find a significant spatial dependence that has been growing over time and characterized by a low distance decay. They find that commuting flows are an important factor in generating spatial dependence, but other forces are responsible for the significant estimated coefficient on the spatially lagged unemployment rate, which remains significant even after commuting flows are controlled for. This result indicates that other factors such as mismatch between the supply and demand sides of the labor market, interregional trade or housing patterns might be at work.

For the U.S., Conley and Topa (2002) examine the spatial patterns of unemployment in Chicago between 1980 and 1990 at the Census Tract level. Their results indicate that there is a strong positive and statistically significant degree of spatial dependence in the distribution of raw unemployment rates, and that this is consistent with models in which agents' employment status is affected by information exchanged locally within their social networks. 
Molho (1995) using 1991 British Census data on unemployment rates at the local labor market area level, find significant spillover effects. According to their estimates, a one-time local demand shock has an impact in the short run on the local unemployment rate, as well as ripple effects to neighboring areas. The immediate unemployment effect is strongest in the area where it originated; while the spillover effect is the strongest after a time lag. They interpret this pattern of behavior as being consistent with a (distributed) lagged migration response to a demand shock. Ultimately, the effects of the demand shock were spread evenly across the country.

Our model of spillovers and correlation of economic activity across location is going to be nonstructural but it is inspired by a growing literature (non structural and structural) that studies how shocks to a specific location impact economic outcomes in close-by locations through migration, trade and other channels (for example learning). See, among, others, Blanchard and Katz (1992), Van Nieuwerburgh and Weill (2010), Fogli and Veldkamp (2011), Davis et al. (2010), Greenstone et al. (2010), and Martin et al. (2011). The last one is particularly relevant for our work as it identifies local spill-overs arising from short run variation in economic activity, hence possibly relevant for business cycle analysis. Another work that studies local correlation of economic activity is Shea (1996), which uses co-movement at the city level to distinguish the hypothesis of local spillovers from the one of common shocks, and which finds evidence for local spillovers. Still, none of these works have explicitly studied the effect of local transmission on business cycle dynamics.

There is also a literature that deals with the difference in long run economic development across locations. For example Desmet and Rossi-Hansberg $(2010,2011)$ document that in the U.S., employment concentration and employment growth vary dramatically across space and across time. To explain these patterns, they develop a dynamic model with endogenous investment in which technology diffuses over space to nearby locations.

Finally in terms of empirical work, recently some authors have used county level data to identify the determinant of aggregate shocks (see, for example, Mian and Sufi 2010 and Mian et al. 2011). This literature, however, abstracts from the role played by geography in the transmission of shocks across time and space, as counties are studied as isolated entities. Also recently Hamilton and Owyang (2012) have used business cycles at the state level to identify separately aggregate shocks from state level shocks, but do not explicitly analyze the interaction between the two.

The paper is structured as follows. Section 2 contains the empirical analysis, Section 3 introduces the model, Section 4 discusses how we set the parameters and Section 5 presents our results. Section 6 concludes. 


\section{Empirical Evidence}

The main goal of this section is to document several spatial properties of business cycles in the United States. Our main data-set is composed of the monthly unemployment rates for 3065 counties in the continental United States, starting in the first month of 1977 and ending in the last month of 2011, as provided by the Bureau of Labor Statistics (BLS). In the first part of the analysis we focus on the most recent recession, while in the second part of the section, to put things in perspective, we compare the spatial features of the recent cycle with those in previous cycles.

One important issue with the data provided by the BLS is data comparability across time. The BLS provides three separate data-sets for monthly county level unemployment: data for the 19771989 period, data for the 1990-1999 period and data for the 2000-2011 period. The BLS suggests that within each data-set unemployment figures are comparable across time and across counties, but that, due to changes in methodology, they are not comparable across data-sets. ${ }^{2}$ For these reasons we treat each data-set separately and study the geographical patterns of unemployment in the recessions that take place in each data-set. Since data is not seasonally adjusted we first apply the X12 census procedure to each county level data series in all the three data-sets to remove seasonal fluctuations. Then, as we want to highlight spatial features of unemployment that are connected to business cycles and not to permanent characteristics of a particular group of counties (for example a group of contiguous counties that are all rural), we remove county fixed effects (i.e. mean county unemployment over the data-set) from each county unemployment series. So from now on, whenever we refer to county unemployment we always refer to data which is seasonally adjusted and in deviations from (within data-set) county mean.

\subsection{Spatial Patterns of the Great Recession}

In figure 1 we use our unemployment data to provide an informal but suggestive illustration of the spatial properties of the recent cycle by plotting several color coded unemployment maps for the counties in our sample. Each map depicts the deviation of unemployment within each county from its long term (2000-2011) mean. The first map (the one in the Northwest corner) is for June 2007, before the start of the recession, and the last one (the one in the Southeast corner) depicts the spatial distribution of unemployment in June 2009, when aggregate unemployment is close to its

\footnotetext{
${ }^{2}$ Indeed we have found that many time series of statistics computed on these datasets display big discontinuities when moving from one data-set to the other.
} 
peak. ${ }^{3}$ Next to each map we report three statistics: The first is simply the aggregate unemployment rate (from the BLS). The second is the standard deviation of unemployment across counties, which captures the spatial dispersion of unemployment deviations from the mean. The third statistic is the spatial autoregressive coefficient which is commonly used in geographical studies to measure the degree of spatial correlation i.e. the overall association between unemployment in each county and unemployment in all nearby counties. ${ }^{4}$

The first feature we want to highlight in the June 2007 map is that there is high spatial correlation of unemployment across counties. The map shows that unemployment (in deviations from means) is not randomly distributed across space but rather there are entire groups of spatially close counties that share either higher or lower unemployment than average. This results in a coefficient of spatial correlation that exceeds 0.79. Moreover (before the start of the recession, when aggregate unemployment is still low), the majority of counties have unemployment close to or below their long term mean. As time goes by and the recession starts (see the December 2007 and September 2008 maps) unemployment does not increase in all counties simultaneously, rather it first increases in a few specific counties, not necessarily located close to each other; this results in a fall of the degree of spatial correlation. As time goes by and the recession deepens, the geographic distribution of unemployment follows an epidemic pattern, i.e. unemployment tends to increase in counties that are closer to counties initially hit with high unemployment (see the December 2008 and March 2009 maps), so that unemployment is high in some concentrated areas and relatively low in others, and this results in an increase in the degree of spatial correlation and of spatial dispersion. As the recession reaches its peak (see the June 2009 map), high unemployment is spread all over the country and both the degree of spatial correlation and spatial dispersion stabilize (and eventually decline).

The evidence displayed in the maps indicates that the location of a given county might be an important determinant of its unemployment dynamics and in particular that its own unemployment might be affected by (and affect) unemployment of its neighbors, suggesting a possible role of geography for the transmission and propagation of business cycle shocks. To better quantify and isolate this effect, we control for a possible source of geographical correlation which arises from geographical specialization. To make a concrete example, think of the auto industry which is affected heavily by the recession, and which is also geographically concentrated around Detroit. This fact will be reflected in a high (and increasing in recession) indicator of spatial correlation;

\footnotetext{
${ }^{3}$ For a similar visual analysis see Egwuekwe (2011)

${ }^{4}$ See the appendix for details on how this coefficient is computed
} 

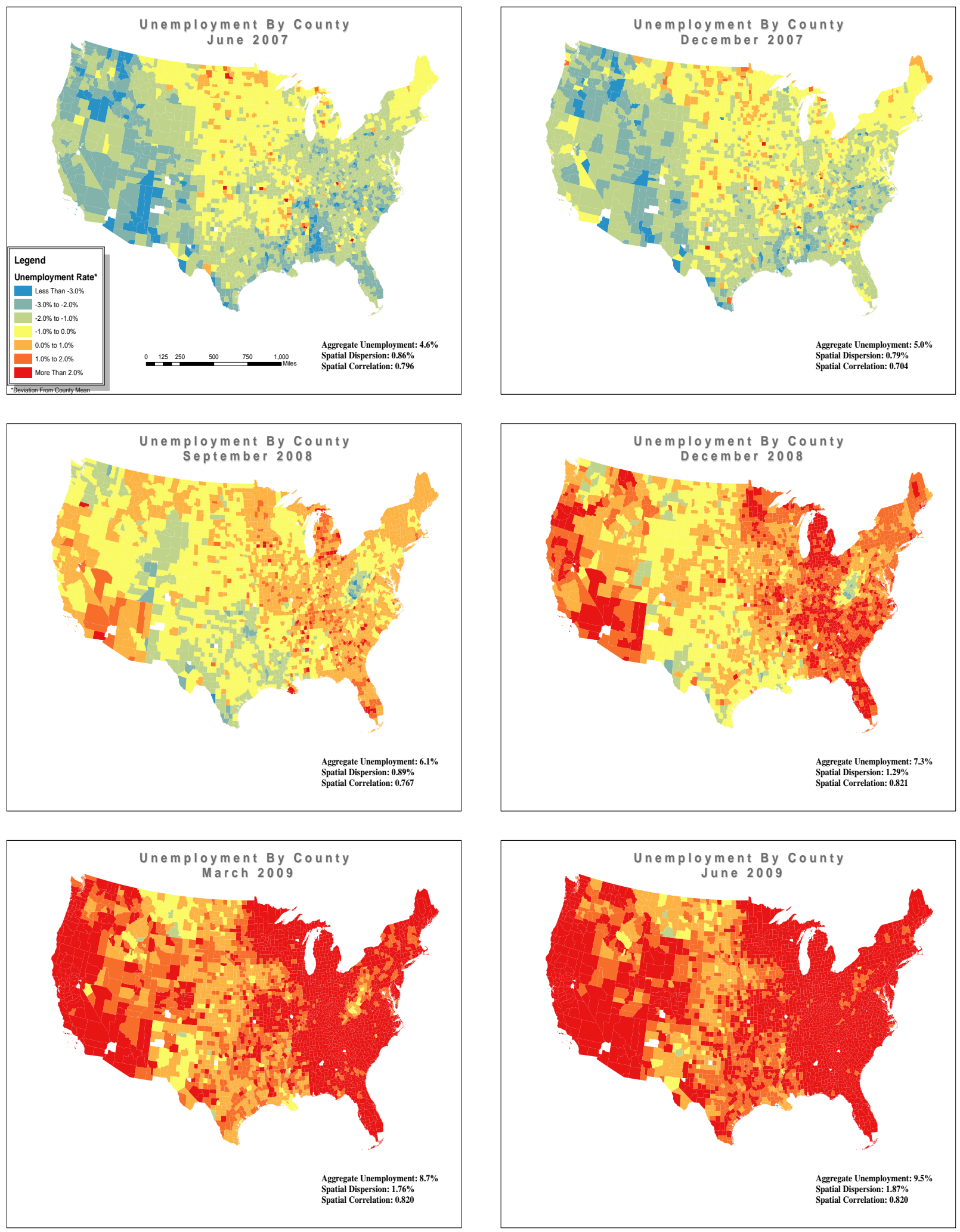

Figure 1: UNEMPLOYMENT MAPS 
but this correlation does not reflect transmission of shocks from one county to the other, but rather a similarity of industrial structure in neighboring counties around Detroit, and the fact that counties with similar industrial structure are hit in a similar fashion by the recession. In order to control for this, in figures 2 and 3 we report time series, during the Great Recession, for spatial correlation and spatial dispersion computed first using county unemployment in deviations from mean (these are the same statistics reported in the maps) and then using the residuals from regressing, period by period, county unemployment on employment industrial composition in 2007 in each county. In particular we compute employment industrial composition in each county using data from the County Business Patterns from 2007. Industrial composition of a county is based on labor share within each sector. Sectors are determined using the first 3 digits from the North American Industry Classification System (NAICS) 2002, which includes 86 sectors. $^{5}$ These controls should pick-up variation in county level unemployment that is due to similarity in industrial structure.

The figures show more clearly the pattern we discussed in the maps above. Spatial correlation is high overall, falls at the start of the recession, increases quite sharply during the recession and then stabilizes at the end of the recession (V shaped pattern). When industrial composition is controlled for, the degree of spatial correlation is lower, but remains significantly different from zero and follows the same pattern as when controls are not included. Spatial dispersion also increases sharply in the midst of the recession and then stabilizes and falls (inverse U shaped pattern), and this pattern is preserved when we control for industrial composition. These patterns suggest that geographic transmission of aggregate shocks between geographically close counties might have played an important role during the Great Recession.

\subsection{Spatial Dispersion and Correlation in Previous Recessions}

In figures 4 and 5 we report, for all other recessions in our sample, the same statistics we reported for the great recession in figures 2 and 3. ${ }^{6}$ Regarding spatial correlation (Figure 4) we would like to highlight how in the 1990, 1982 and 1980 recessions the correlation follow a pattern similar to the one in the Great recession, falling before and at the start of the recession, increasing sharply

\footnotetext{
${ }^{5}$ When sectoral employment is reported with a range, we use the midpoint of the range to compute labor share. Additional information can be found from the County Business Pattern web site http://www.census.gov/econ/cbp/index.html

${ }^{6}$ When we control for industrial structure in figures 4 and 5 we use 2000 (for the 2001 recession), 1990 (for the 1990 recession) and 1980 (for the 1980-82 recession) county/sectoral employment data from the County Business Patterns. The 2000 labor shares are based on the three digit 1997 NAICS (82 sectors). The 1990 and 1980 labor shares are based on the available classification closest to the three digit NAICS, which is the two digit Standard Industrial Classification (SIC) System 1987 (69 sectors, for the 1990 recession) and 1972 (68 sectors, for the 1980 recession) definitions respectively.
} 


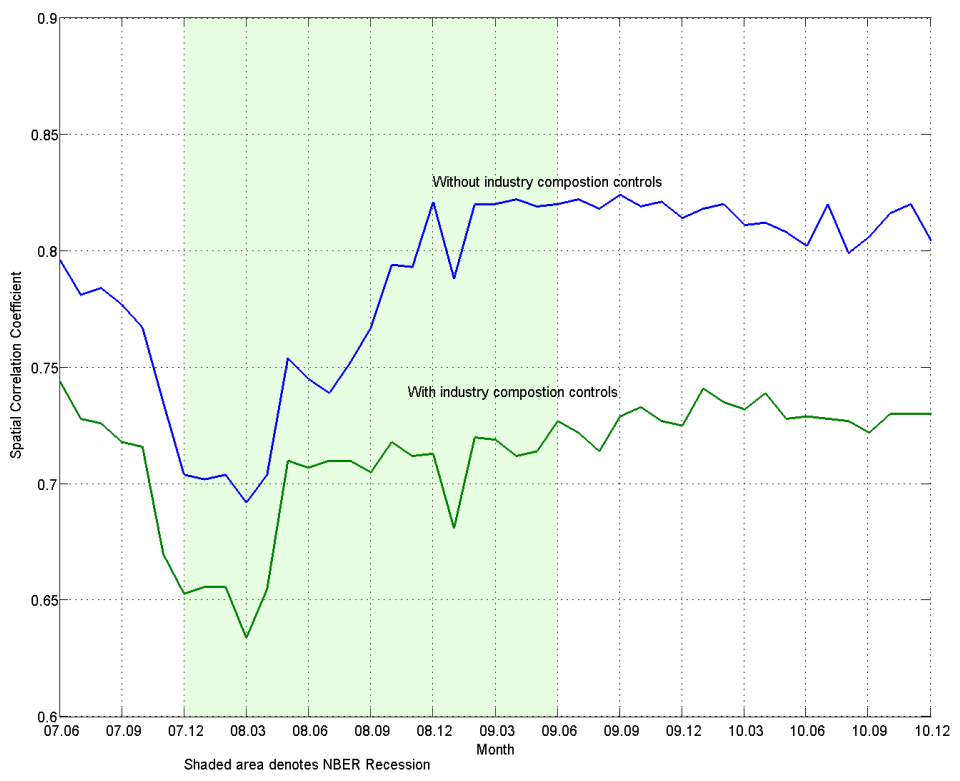

Figure 2: Spatial Correlation During the Great Recession

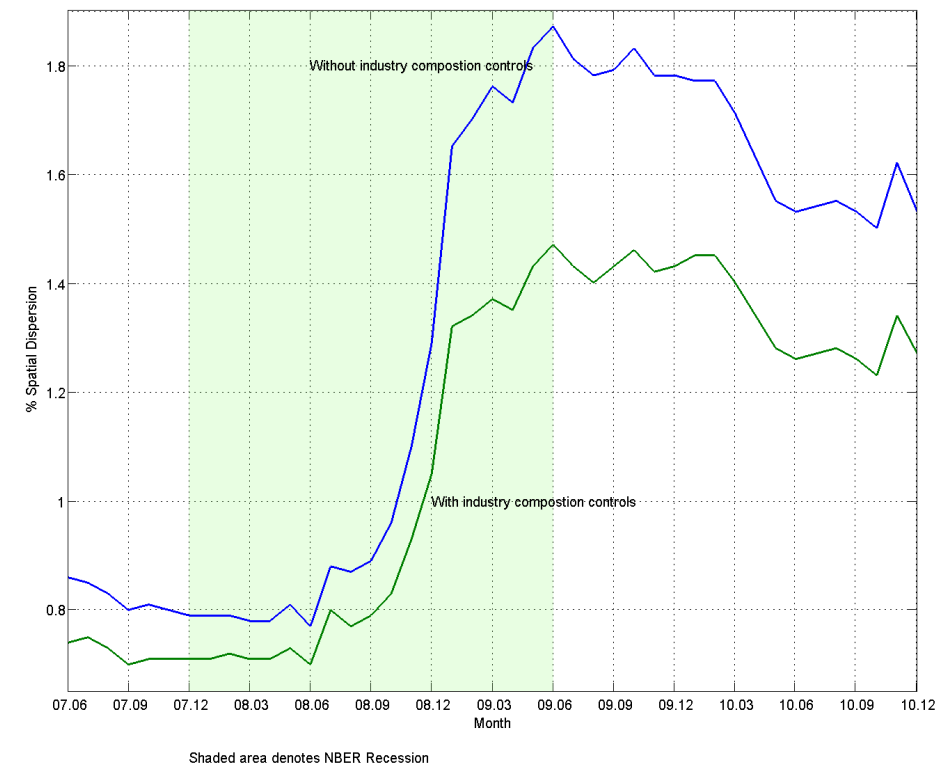

Figure 3: Spatial Dispersion During the Great Recession 
during the recession and then stabilizing towards the end of the recession. In the 2001 recession the pattern is qualitatively similar, although the decline in spatial correlation lasts all throughout the recession. Regarding spatial dispersion (Figure 5) again the pattern for the 1990, 1982 and 1980 recessions is similar to the one observed in the Great Recession, with a sharp increase in dispersion during the recession, with a stabilization and fall thereafter. Again the 2001 recession appears to be different, with the spatial dispersion registering virtually no increase. One possible reason why the spatial patterns of the 2001 recession are different is the relatively minor increase in unemployment that took place in that recession.

We conclude our empirical analysis summarizing its two main findings: the first is that at any point in time, unemployment across counties is significantly spatially dispersed and spatially correlated. The second is that during most recessions both spatial dispersion and spatial correlation have distinctive patterns which cannot be explained simply by differences/similarities in industrial composition across locations. In the next section we put forward the hypothesis that these patterns are an indication of the geographical diffusion and the propagation of an aggregate business cycle shock. 

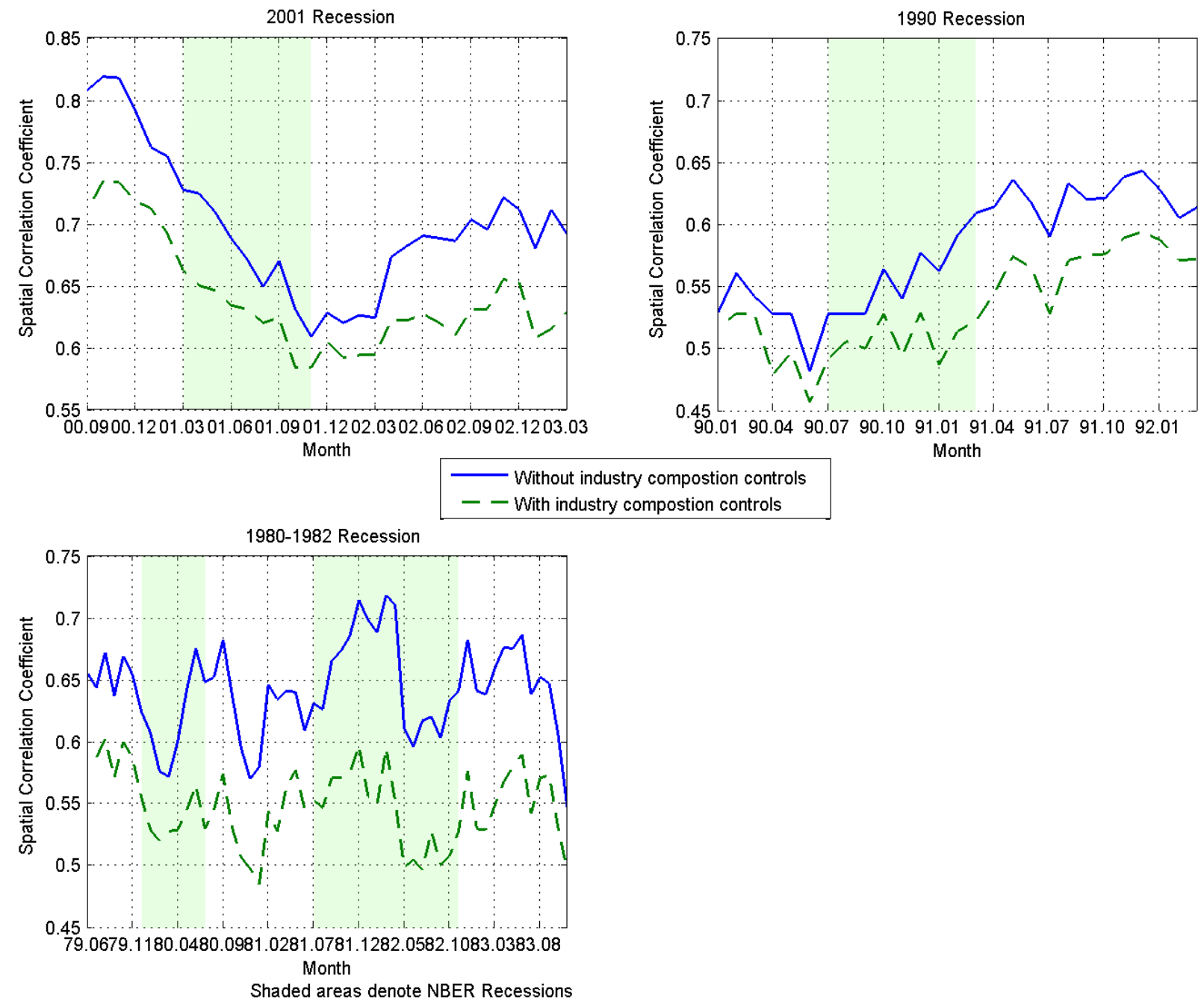

Figure 4: Spatial Correlation During Past Recessions 

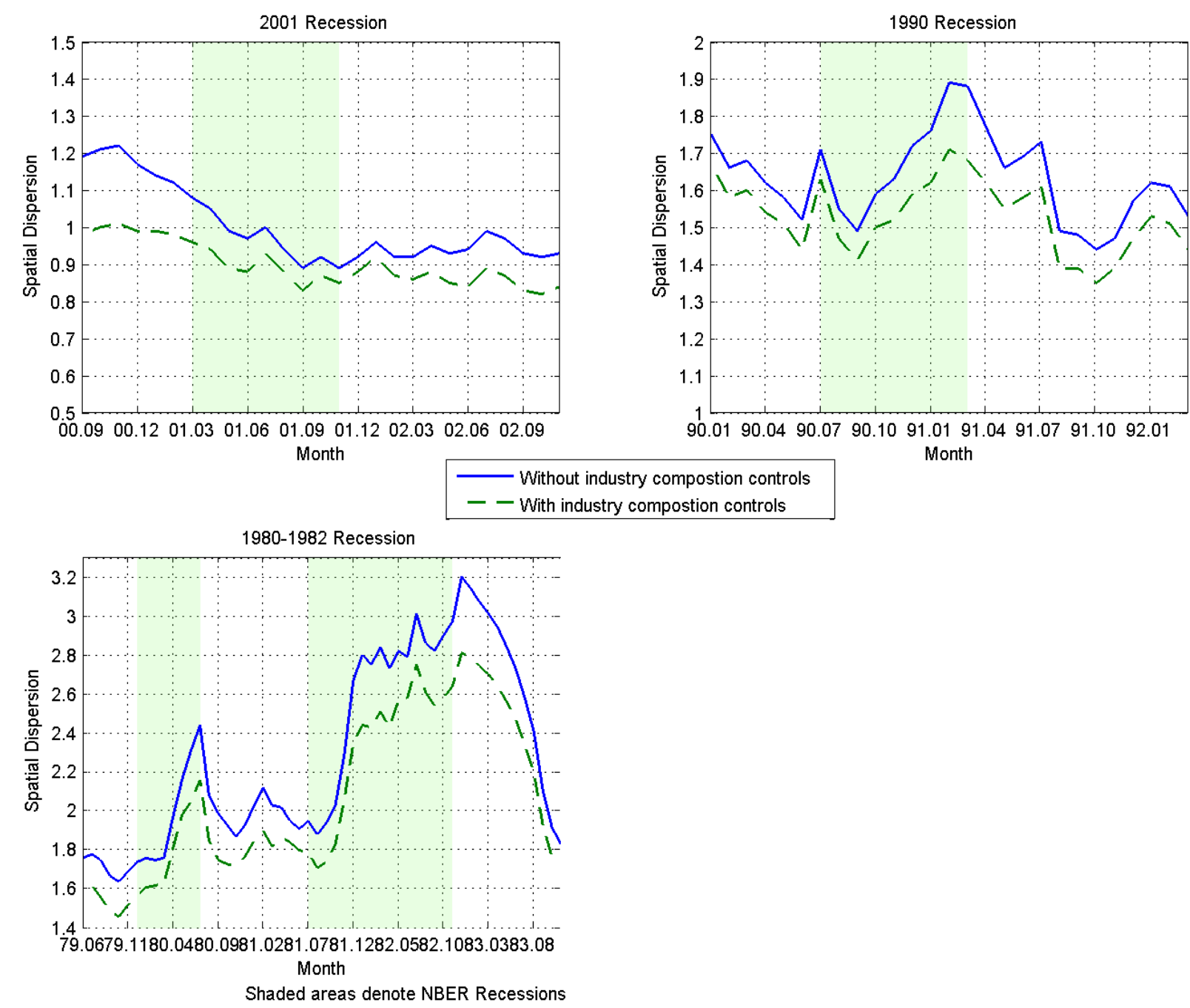

Figure 5: Spatial Dispersion During Past Recessions 


\section{A mechanical model}

In this section we present a simple (and mechanical) model of unemployment in a country with many counties. The purpose of the model is to illustrate and quantify, using the data presented in the previous section to discipline the model, the role of spatial transmission and spatial heterogeneity as a mechanism of amplification and propagation of aggregate shocks. Hence the key elements of the model are a basic geographic structure, a county specific shock, an aggregate shock and a mechanism of interaction between the two. We now describe these elements in detail

\section{Spatial Structure}

The economy consists of a finite number of contiguous counties (indexed by $i$ ) of equal size, located on a plane as depicted in Figure 6 where each square represent a county. Each county has a set of neighbors which are the counties which share a border with the given county. The black county in the figure has all the grey counties as neighbors.

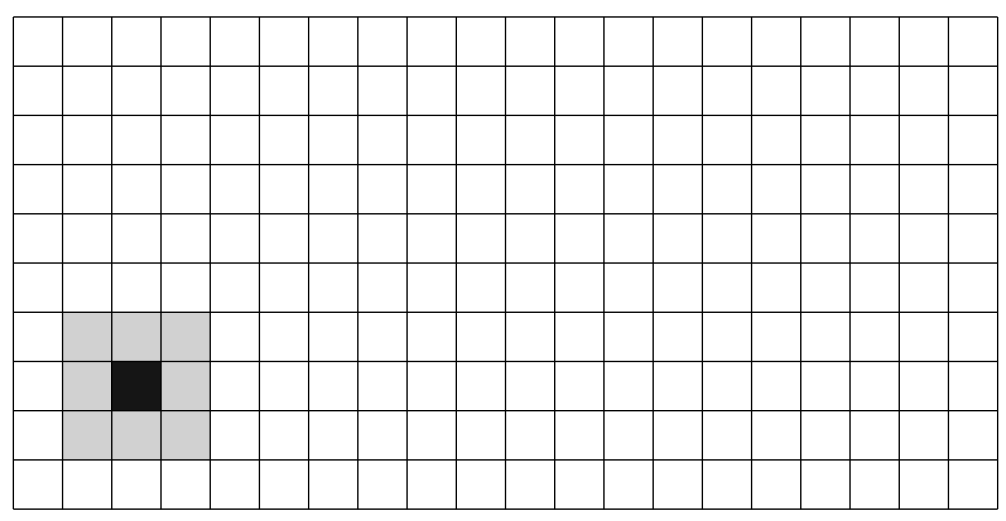

Figure 6: Map of the Model Economy

\section{County specific shocks}

Unemployment in county $i$ in period $t$, denoted by $u_{i t}$ is modeled as a Markov chain that can take two values, $u_{h}$ and $u_{l}$, with $u_{h}>u_{l}$. In each period, each county draws a fundamental county specific shock that we denote by $\varepsilon_{i t}$. With these shocks we want to capture the effects of county specific conditions (i.e. local labor market frictions, local productivity or local demand, etc.) on the dynamics of local unemployment, ceteris paribus. A higher value of the shock here indicates better conditions and, as we'll see later, it pushes down unemployment in that county. We assume that these shocks are independently and identically distributed across counties and across time, according to a uniform distribution with support on the unit interval. We introduce the possibility 
of spatial transmission by defining an "effective" shock for county $i$, given by

$$
\hat{\varepsilon}_{i t}=(1-\lambda) \varepsilon_{i t}+\lambda \frac{1}{N_{i}} \sum_{j \neq i} w_{i j} \varepsilon_{j t}
$$

where $\lambda$ is a key parameter that captures the simultaneous impact of shocks in its neighbors on county $i$ unemployment. $N_{i}$ is the number of neighbors of county $i$ and $w_{i j}$ is equal to 1 if county $j$ is a neighbor of $i$ and 0 otherwise. The special case in which shocks in neighboring counties do not have any effect on local unemployment dynamics is captured by $\lambda=0$.

We now specify how effective shocks $\hat{\varepsilon}_{i t}$ affect unemployment transitions by defining cut-offs, specific for each county and for each state, given by

$$
\left[\begin{array}{c}
C_{h}=p+d_{t}+\phi \sum_{j \neq i} w_{i j} u_{j t-1} \\
C_{l}=1-q+d_{t}+\phi \sum_{j \neq i} w_{i j} u_{j t-1}
\end{array}\right]
$$

The first line of the expression above represents the cutoff for a county which currently has high unemployment: if the county draws an effective shock $\hat{\varepsilon}_{i t} \leq C_{h}$ it will stay in the high unemployment state and if $\hat{\varepsilon}_{i t}>C_{h}$ the county will switch to low unemployment. The second line instead represents the cutoff for a low unemployment county: if the county draws an effective shock $\hat{\varepsilon}_{i t} \geq C_{l}$ then the county will stay in the low unemployment state and if $\hat{\varepsilon}_{i t}<C_{l}$ the county will move to high unemployment.

Note that all the cutoffs above have three terms which serve three purposes.

The first terms in each cutoff are functions of fixed parameters ( $p$ and $q$ ) which determine the probability that, when county unemployment is in a given state, it remains in that state. In particular higher $p$ and/or $q$ means a higher probability of not switching states and thus results in a more persistent process for county level unemployment.

The second term $d_{t}$ captures aggregate shocks which affect all counties. Notice that when $d_{t}$ is high the whole economy will have higher unemployment as all counties that are in the high unemployment state are more likely to remain in that state and all counties with low unemployment are more likely to switch into high unemployment.

The third term $\phi\left(\sum_{j \neq i} w_{i j} u_{j t-1}-u_{i t-1}\right)$ captures the spillover effect that lagged unemployment in neighboring counties (relative to the county in question) can have on current unemployment in any given county; in particular $\phi>0$ implies that counties surrounded by neighbors with unemployment higher than their own are more likely to experience increasing unemployment. 
We now have all the elements to characterize numerically, given an initial distribution of unemployment rates across counties, the evolution of unemployment across counties and across time.

Before we present our results we would like to stress that ideally one would want to write down a structural model of a local labor market where, the parameter $\lambda$ reflects common structural shocks and the parameter $\phi$ captures worker's mobility across counties. Think, for example, of an industrial district comprised of several geographically close counties which specialize in the production of similar varieties of a given good. One county might develop a new technology or experience a change in demand for its variety and such a shock would affect its rate of unemployment; $\lambda$ would capture how much this local event affects the neighboring counties. The parameter $\phi$ instead would capture how fast workers in, for example, a high unemployment county can move, seeking to work in neighboring counties with a lower unemployment rate, thereby transmitting unemployment to those counties (see, for example, Patacchini and Zenou 2007).

In this work we capture these economic mechanisms with two reduced form parameters $\lambda$ and $\phi$, so the contribution of this part is not so much to provide a serious attempt to model the interaction of local labor market with aggregate shocks, but rather to provide a simple evaluation tool to assess whether this interaction can be important.

\section{Calibration}

In order to characterize the path for local and aggregate unemployment in the economy described above we perform simple simulations. We first assume that the model economy is comprised of $100 \times 30=3000$ counties which approximate the US counties (3065) in our data set. In terms of time period we choose to focus on our latest data-set, i.e. the 12 years spanning from the January 2000 to December 2011. In general we will set parameters so that the statistics produced by the model match both aggregate unemployment and some selected county level statistics.

In particular we pick the whole time series for the aggregate shock $d_{t}$, plus the structural parameters (summarized in table 1) of the model 
Table 1. Parameter values

\begin{tabular}{lll}
\hline \hline Parameter & Description & Value \\
\hline$u_{h}$ & High unemployment & $9.5 \%$ \\
$u_{l}$ & Low unemployment & $4 \%$ \\
$p$ & Probability of staying in high unemployment & 0.68 \\
$q$ & Probability of staying in low unemployment & 0.82 \\
$\lambda$ & Contemporaneous transmission of shocks & 0.75 \\
$\phi$ & Spatial Impact of Lagged unemployment & 3.0 \\
\hline \hline
\end{tabular}

so that the model reproduces the county level targets summarized in table 2 and the aggregate time series for unemployment, reproduced in figure 7. All targets depend on all parameters so we use a global search algorithm to get as close as possible to all targets. Figure 7 suggests that the model does a very good job in matching aggregate data and Table 2 suggests it does a reasonable job in matching county moments. The fact that we can closely match aggregate data is not surprising as the model can capture well the path for aggregate recessions and recoveries with increasing and falling $d_{t}$. In principle one could think that our model is flexible enough so it can hit all 4 moments in Table 2 (plus the aggregate data) exactly. In practice we have found it difficult to achieve an exact match and thus the particular parameter configuration we have chosen reflects our best (though not exact) overall match. ${ }^{7}$ After all parameters are set we can use the model to assess the impact of spatial transmission on the impact and propagation of aggregate shocks.

Table 2. County Level Calibration Targets

\begin{tabular}{lll}
\hline \hline Moment & Data & Model \\
\hline Spatial Dispersion (Avg. across time) & 0.010 & 0.016 \\
Spatial Correlation (Avg. across time) & 0.696 & 0.607 \\
Lagged Spatial Correlation $^{8}$ (Avg. across time) & 0.057 & 0.047 \\
Autocorrelation unemployment (Avg. across counties) & 0.894 & 0.895 \\
\hline \hline
\end{tabular}

Note: County level moments in the data are computed using seasonally adjusted county level unemployment from 2000.1 to 2011.12. Before computing moments we remove county and time fixed effects. Moments from the model are computed across several simulations with the same number of periods as in the data. For better comparability time and county fixed effects are also removed from artificial data.

\footnotetext{
${ }^{7}$ Obviously we have experimented with many alternative parameterizations that achieve a similar match quality of aggregate data, but slightly different county level calibration targets. Our results are qualitatively robust to those changes. We have also experimented with modelling unemployment as a three (as opposed to two) state Markov Chain. We found that, despite the additional parameters, this modelling choice did not produce a significant better fit, so we stayed with the two state representation.

${ }^{8}$ To obtain this coefficient we regress, in the data and in the data generated by the model, county level unemployment on its own lagged value and on the lagged value of the neighbors unemployment. The Lagged spatial conditional correlation is the estimated coefficient on lagged neighbor unemployment.
} 


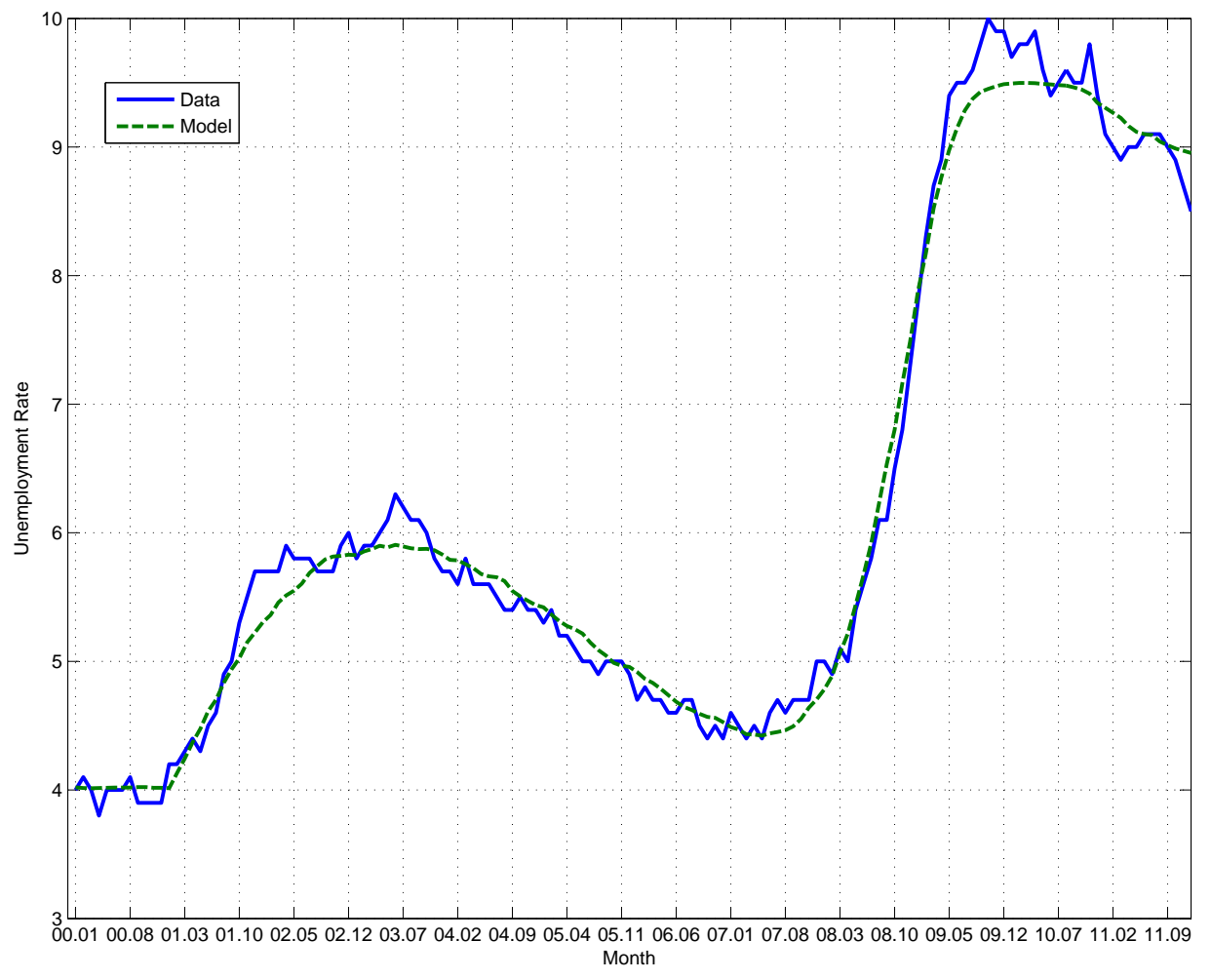

Figure 7: Aggregate Unemployment Rate: Data and Model 


\section{Results}

Our first result is about the ability of the model to replicate the pattern of spatial dispersion and spatial correlation during recessions (the paths reproduced in figures 2,3,4 and 5). Note that the model is calibrated to match average (over 2000.1 to 2011.12) spatial correlation and dispersion but not their movement over the cycle. To assess this we feed the model the process for $d_{t}$ that generates aggregate unemployment in figure 7 above, and then in figure 8 we plot the path of spatial correlation and spatial dispersion generated by the model during the two recessions in our sample.
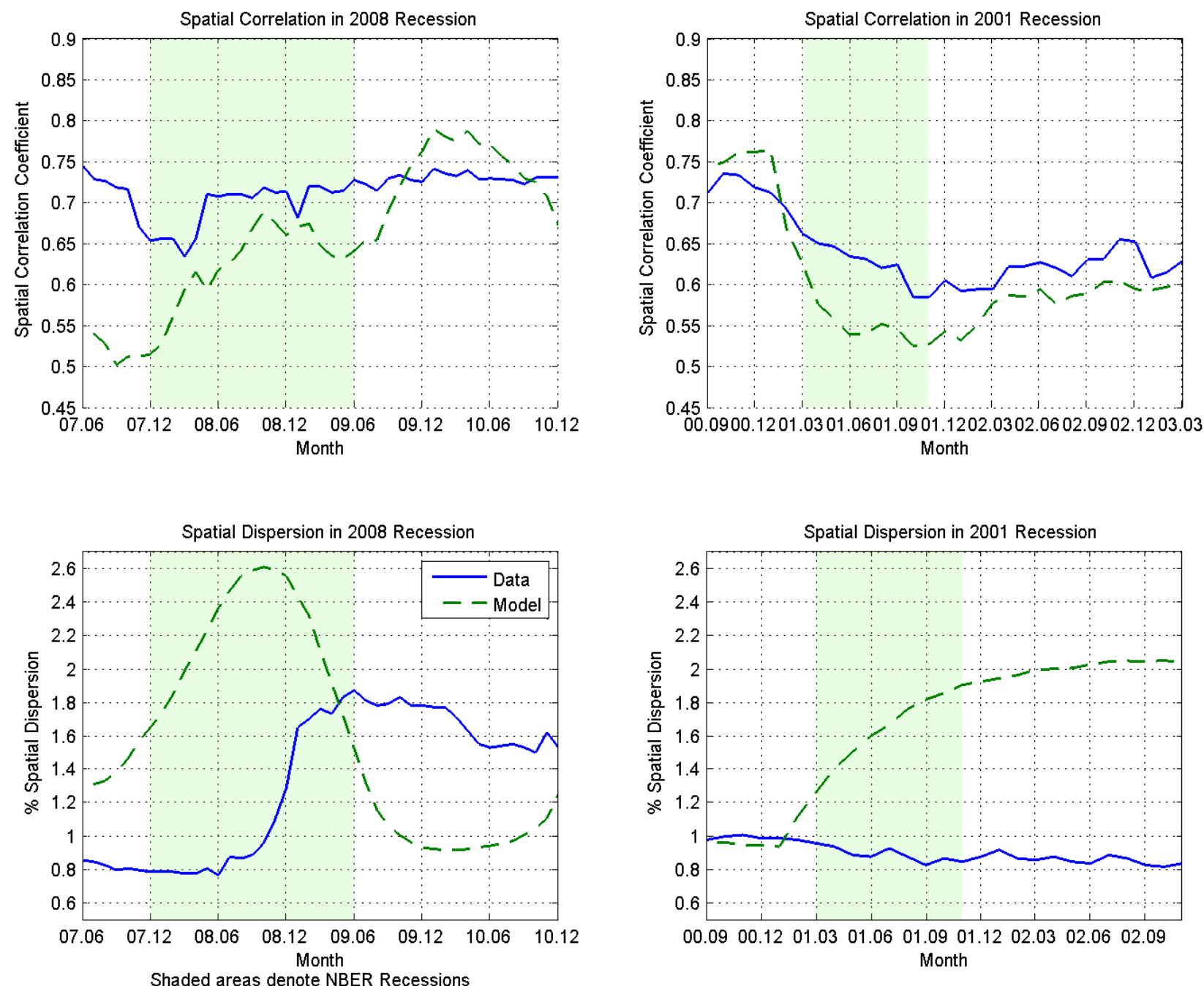

Figure 8: Spatial Correlation and Dispersion: Data and Model

Let's start with spatial correlation in the two recessions (the top two panels). Qualitatively the 
model display the V-shaped pattern discussed earlier. Spatial correlation falls before the recession then increases and finally stabilizes. Quantitatively though the model over-predicts the increase in spatial correlation that took place over the great recession.

The bottom two panels of the figure display spatial dispersion during the two recessions. In both recessions the models predicts an increase in spatial dispersion, followed by a stabilization and a fall. This pattern conforms with the data during the Great Recession (although the model over-predicts both the increase and the fall) while it does not during the 2001 recession. As we already noted, the 2001 recession stands out in this respect, while in all other previous recessions in our sample spatial dispersion displays a pattern similar to the one predicted by the model.

Before we move to our final experiment we would like to discuss why the model generates these patterns in spatial dispersion and spatial correlation during the recession. The path of spatial dispersion is easy to understand. Before the recession, aggregate unemployment is low and dispersion is also low as most counties are in the low unemployment state. The aggregate shock that triggers the recession is modeled as an increase in probability of switching to high unemployment (from low unemployment) and a fall in the probability of switching to low unemployment (for counties which are in high unemployment). This implies that when the recession hits, the fraction of counties with high unemployment will increase from a number close to 0 to a number close to 0.5 and this will in general increase spatial dispersion. If the fraction stays around 0.5 (i.e. the majority of counties are NOT in high unemployment) then the spatial dispersion stabilizes, as it does during the mild 2001 model recession. If the fraction of high unemployment counties goes toward 1 then the spatial dispersion falls again as the distribution is now concentrated around the high unemployment state (as it does during the strong 2008 model recession).

The path of spatial correlation is a bit more subtle to understand. Before the recession hits spatial correlation is fairly high as the economy has been in an expansion for quite a long time and spatial effects (i.e. the parameters $\lambda$ and $\phi$ ) induce the formation of large clusters of low unemployment with small clusters of high unemployment. As the recession hits, some of the low unemployment clusters are broken by the emergence of high unemployment in some counties and thus spatial correlation falls. As the recession progresses, the spatial effects take over again and contribute to the creation of large high unemployment clusters, inducing an increase in spatial correlation, and thus the $\mathrm{V}$ shape.

Overall we believe our model highlights mechanisms of spatial transmission of unemployment that interact with aggregate shocks. These mechanism generate patterns that are broadly similar 
to what we see in the data. Obviously our model is way too simple and broad-brush to hope that it could provide a full quantitative account of the observed empirical patterns. Still we find it instructive to highlight these mechanisms and, in our next result, to evaluate their impact on the transmission and amplification of business cycles.

Our second result has to do with the importance of the local transmission effects for the impact of aggregate shocks. In order to evaluate this, we feed our model the same aggregate shocks $\left(d_{t}\right)$ we used in the previous figure, keep all other parameters unchanged and evaluate the aggregate unemployment response to the shock, when the local contemporaneous transmission of idiosyncratic shocks is lowered (i.e. lowering the parameter $\lambda$ to 0.375 from 0.75 ). The results of this experiment are depicted in figure 9. Notice first that smaller spatial effects have an ambiguous effect, depending on the size of the recession. In particular the figure suggests that with weaker spatial effects the 2001 recession would have been sharper and bigger, so that spatial effects have had a muting effect on that particular cycle. The figure though also suggests that with weaker spatial effects the 2008 recession would have been a bit milder and not as persistent, suggesting, for this recession, an amplification role of spatial effects.

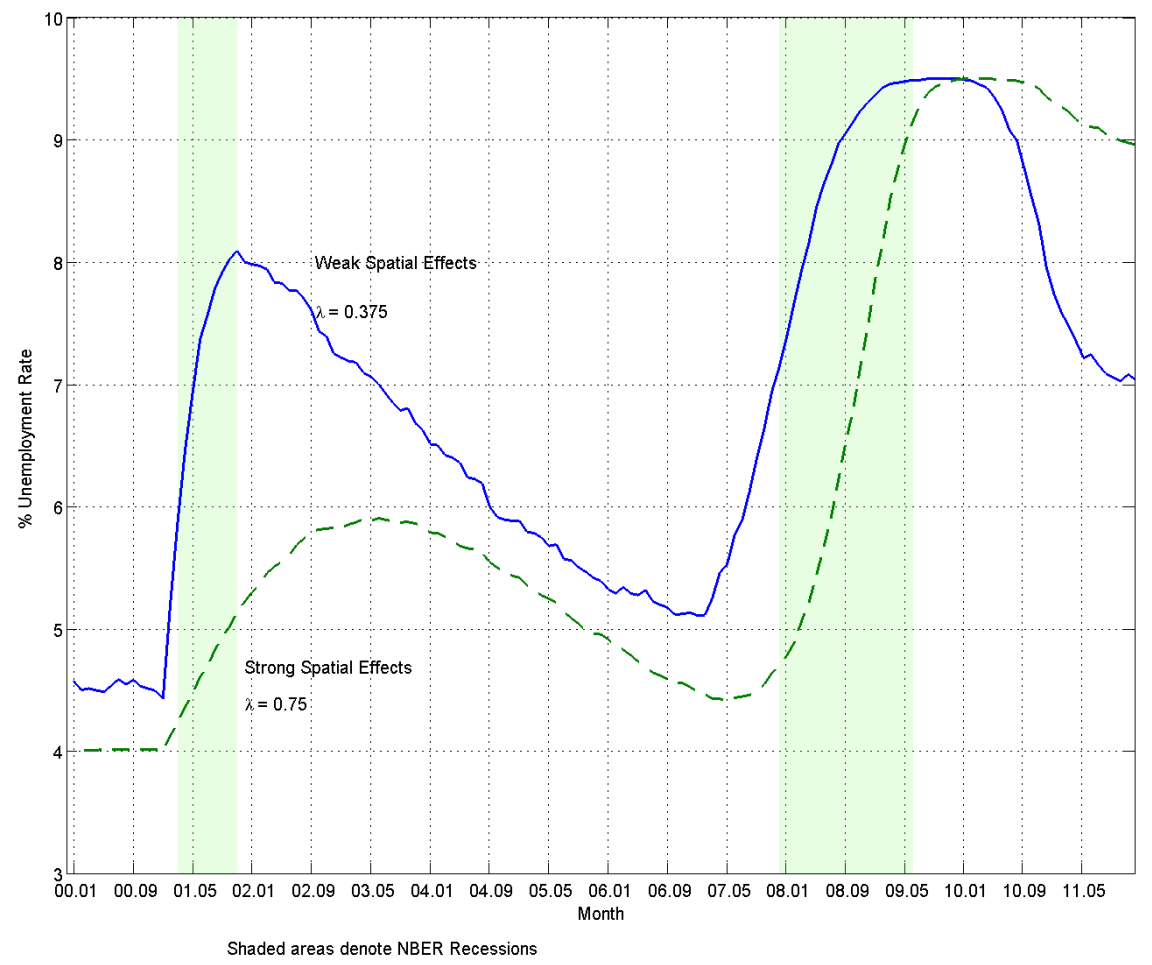

Figure 9: UnEMPLOYMENT CYCLES WITH WEAK AND STRONG SPATIAL EFFECTS 
To understand why this is the case consider figure 10. The two bell shaped curves in each panel represent the distribution of effective shocks $\hat{\varepsilon}_{i t}$ hitting county $i$ in period $t$, in two economies: one with with strong $(\lambda=0.75)$ and the other with weak $(\lambda=0.375)$ spatial effects. With strong spatial effects the effective shock puts more weight on the average of the shocks of the neighbors, so its distribution is more concentrated around the mean. The leftmost vertical lines in both panels represent the cutoffs for the low unemployment state, for a given aggregate shock $d_{t}$ : for values of $\hat{\varepsilon}_{i t} \leq C_{l}\left(d_{t}\right)$ the county switches to high unemployment. The vertical line to the right in the left panel represents the shift of the cutoff after a small aggregate shock $d_{t}^{\prime}$ (like the 2001 recession) hits. (Part of) the increase in aggregate unemployment that results from this shock is given by the area between the two lines $C_{l}\left(d_{t}\right)$ and $C_{l}\left(d_{t}^{\prime}\right)$ and below the bell shaped curves. Note that this implies that the economy with weak spatial effect will suffer a stronger increase in unemployment. This is because for small shocks the effect of neighbors, by reducing idiosyncratic volatility, reduces the fraction of counties with bad realization and thus "helps" the economy cope with aggregate shocks.

Now moving to the right panel, the rightmost vertical line represents the shift of the cutoff after a large aggregate shock $d_{t}^{\prime \prime}$ (like the 2008 recession) hits. Observe that in this case the increase in unemployment is larger in the economy with strong spatial effects, i.e. when the shock is large, lower idiosyncratic volatility is no longer a muting but a magnifying effect. When the aggregate cut-off moves $C_{l}\left(d_{t}\right)$ to $C_{l}\left(d_{t}^{\prime \prime}\right)$ then, in the economy with strong spatial effects, all counties, because the distribution is so concentrated, fall into high unemployment. When the distribution is more disperse (the low $\lambda$ case) even for the large shock, some counties avoid high unemployment, due to extremely positive realizations of their idiosyncratic shocks. So for large shocks the effect of neighbors, by reducing idiosyncratic volatility, reduces the fraction of counties that avoid switching and thus "hurts" the economy in dealing with aggregate shocks.

Obviously this result does not necessarily prove the importance of spatial transmission effects in the data, as it is dependent on the model. However, it suggests that local transmission mechanisms can have big amplification effects on the magnitude and duration of unemployment cycles. Also, importantly, our simple model includes a reduced form mechanism through which high unemployment can transmit from one county to another but it is silent on the exact source of the transmission. We would like to conclude this section by exploring a plausible mechanism, namely housing prices, which might be relevant for the geographic transmission of unemployment, especially during the Great Recession. The underlying idea is that changes in housing prices in a given county can affect unemployment in that county (for a specific channel that can cause this see Mian 


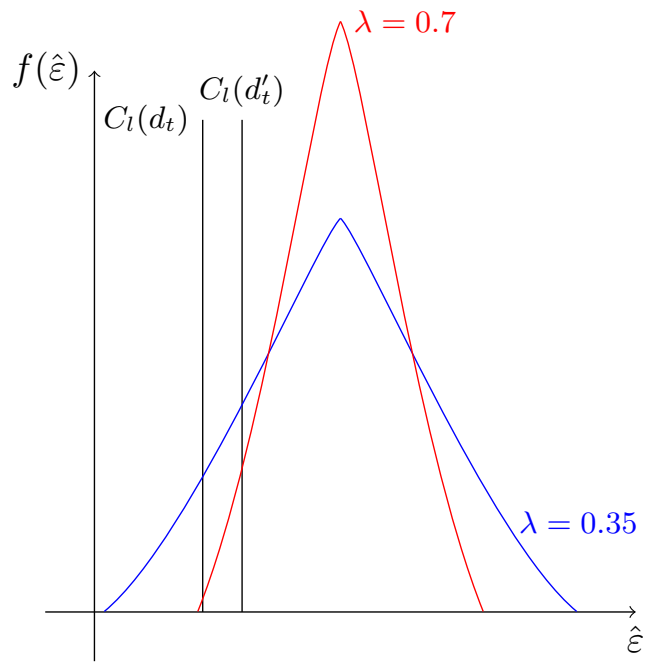

a) Small shock

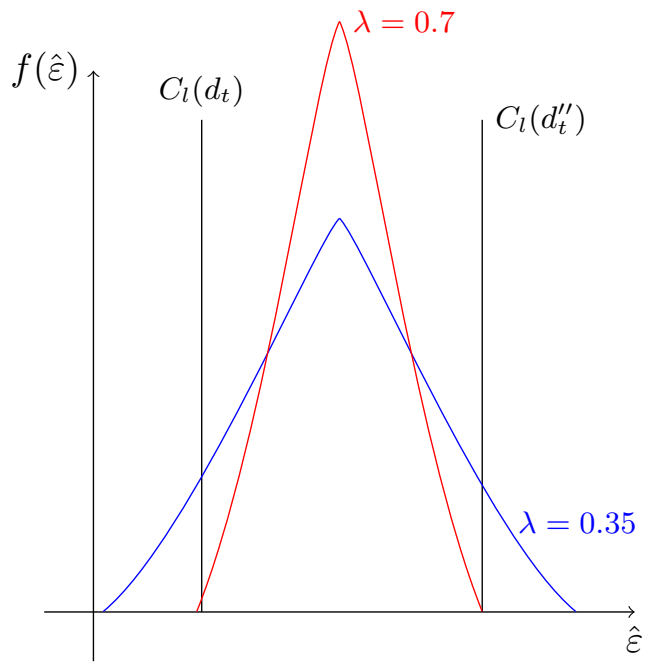

b) Large shock

Figure 10: Spatial EFFECTS With LARGE AND SMALl ShOCKS

et al. 2011). At the same time, through mobility of households, it is plausible to think that changes in housing prices in a given county will affect changes in housing prices in neighboring counties (see for example the work of Campbell et al. 2011). It follows that, through housing prices, high unemployment can transmit from one county to its neighbor.

Using county level monthly price data provided by Zillow ${ }^{9}$, we examine the geographic properties of the evolution of housing prices. Figure 11 shows the progression of the of housing prices, in deviation from their long term mean, over time in all the counties in Florida for which we have data, from early 2007 (when prices were at their peak) to early 2009 (as they reached their bottom). The main point of the figure is to show that the housing price decline seems to follow the same spatial patterns as unemployment. In early 2007 prices fall in sparse location around the coasts and over time price fall in nearby locations until they reach a uniformly low level across the state.

Figure 12 summarizes this pattern (including also the period of housing price boom), displaying the graph for spatial correlation in housing prices, and it compares to the spatial correlation of unemployment for the same set of counties in Florida. The figure shows that the spatial diffusion of housing prices and unemployment are strikingly similar across the whole period of housing boom and bust, suggesting that housing prices might indeed be an important factor in the spatial transmission of unemployment.

\footnotetext{
${ }^{9}$ Additional information on the Zillow data is provided in the Appendix
} 

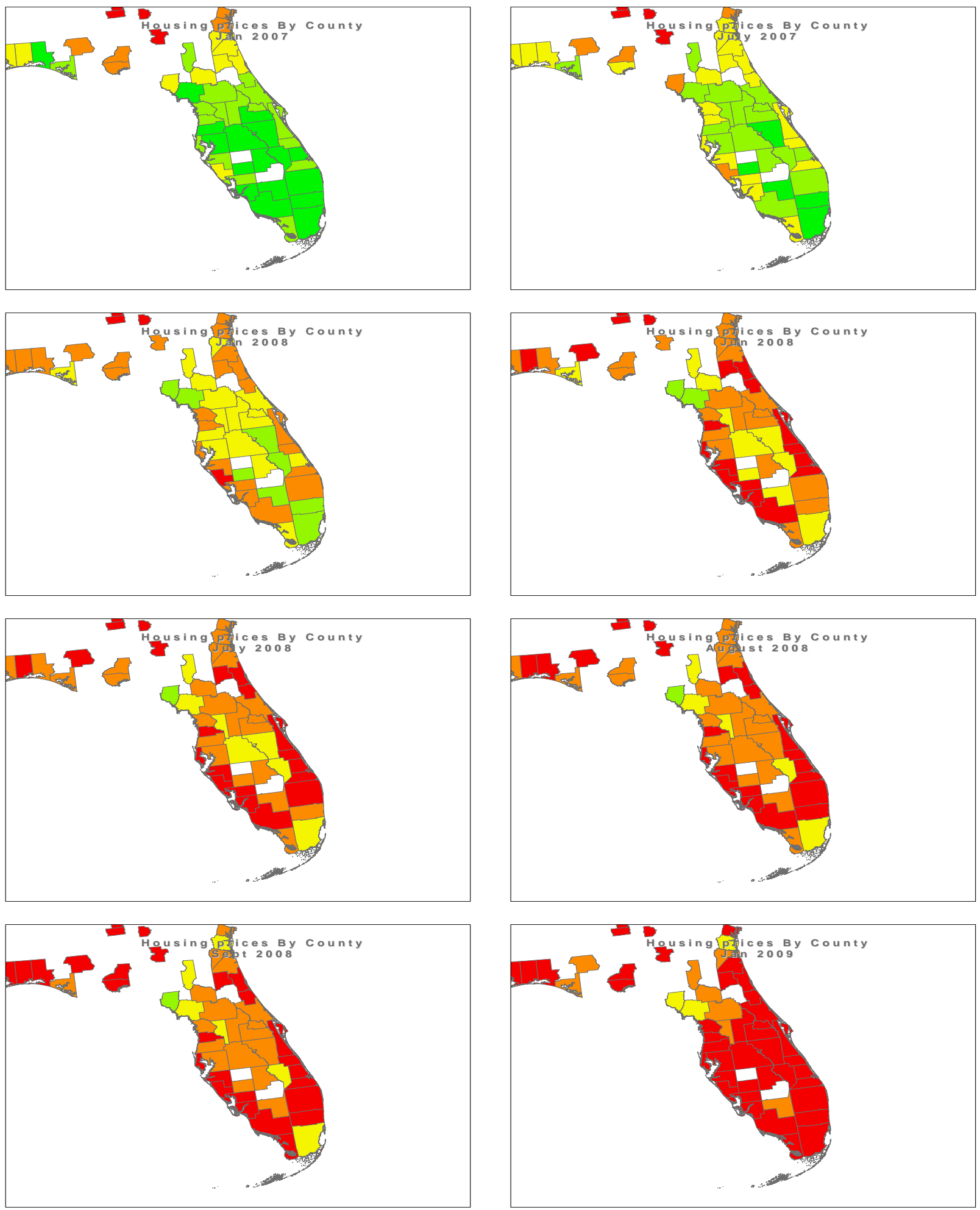

Note: Warmer colors correspond to lower housing prices

Figure 11: The SPATIAL DIFFusion OF HOUSING PRICES BUST IN FLORIDA 


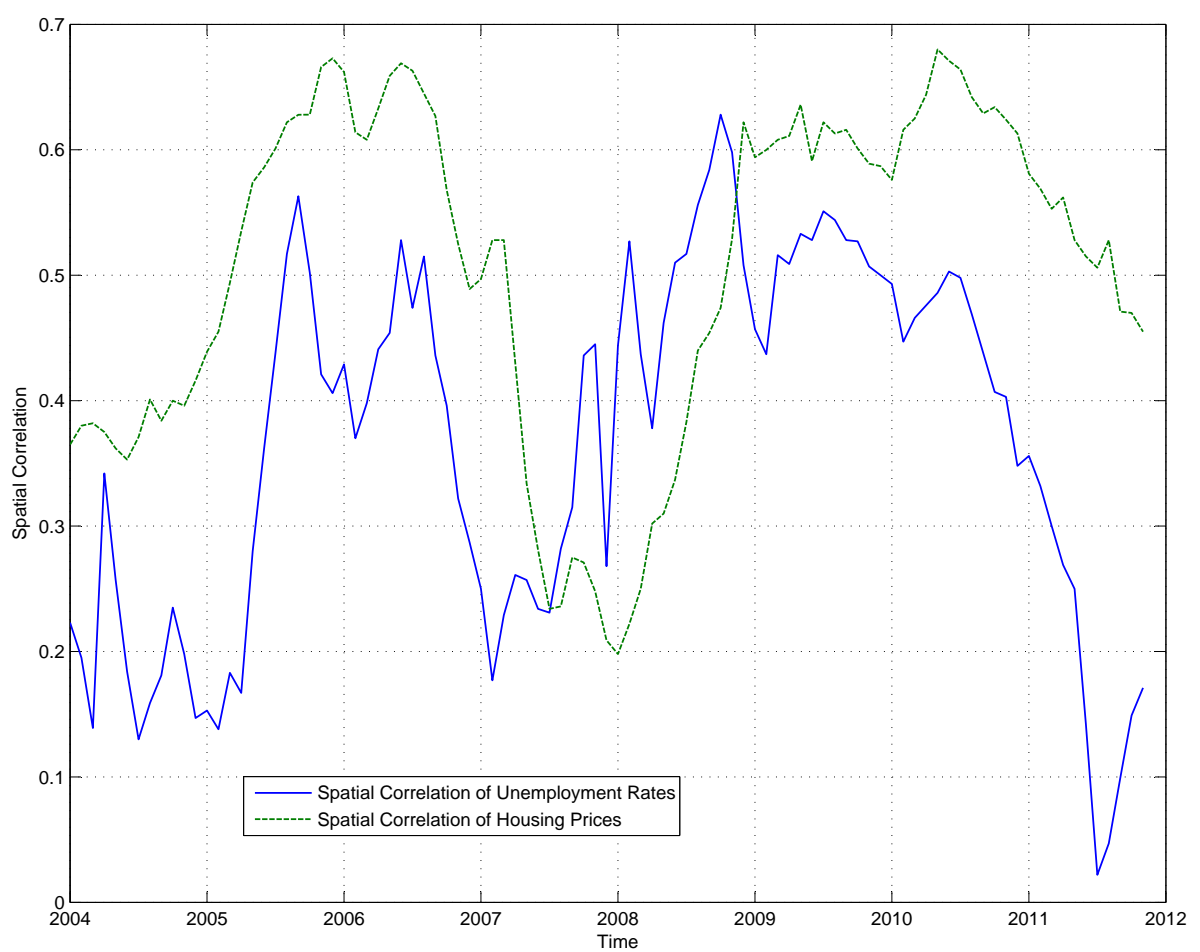

Figure 12: Spatial CORRElation OF UNEMPlOYMENT AND OF HOUSING PRICES: FloRIDA 20042011 


\section{Conclusions}

The main contribution of this paper is to argue that local, geographical factors, which are usually not used in macro analysis might be very important to understand aggregate business cycle dynamics. It suggests that a more detailed study of the exact channels through which economic activity is transmitted locally (see for example the recent work of Fogli and Veldkamp 2011 who focus on learning in labor markets and the work of Campbell, Giglio, and Pathak 2011 who focus on the effect of foreclosures on local housing prices) might also have a big macro payoff.

\section{Appendix}

\section{A The Spatial Autoregressive Model}

To measure the association between unemployment in one county and its neighbors we use the following so-called spatial lag model. 10

$$
\begin{aligned}
u_{i t} & =\rho_{t} \frac{1}{N_{i}} \sum_{j \neq i} w_{i j} u_{j t}+X_{i t} \beta_{t}+\varepsilon_{i t} \\
\epsilon_{i t} & \sim N\left(0, \sigma^{2} I_{n}\right)
\end{aligned}
$$

where $u_{i t}$ represents the de-meaned unemployment rate for county $i$ in period $t$ and $\rho_{t}$ is called the spatial autoregressive coefficient and describes the overall association between unemployment in each county and unemployment in all nearby counties. Here $w_{i j}$ is an element of a spatial weights matrix $W$ in which the element in column $j$ of row $i$ equals 1 if counties $j$ and $i$ share a border and 0 otherwise, note that $w_{i i}=0$ for all $i . X_{i t}$ is a standard matrix of (optional) control variables and $\varepsilon_{i t}$ is assumed to be a normally distributed error term.

As demonstrated in LeSage (1999), the inclusion of a spatially lagged dependent variable introduces an endogeneity which biases the standard OLS estimation of $\rho_{t}$. To help further illustrate this endogeneity, consider a large positive shock in $\varepsilon_{i t}$. This shock increases the unemployment rate $u_{j t}$ of bordering county $j$ by the amount $\rho_{t} \frac{1}{N_{j}} w_{j i} \varepsilon_{i t}$ which in turn reflects a portion back to county $i$. This transmission across counties violates the strict exogeneity assumption required by OLS (i.e. $E\left[\varepsilon_{i t} \mid \frac{1}{N_{i}} \sum_{j \neq i} w_{i j} u_{j t}\right] \neq 0$ ). In order to correct for this bias we employ the maximum

\footnotetext{
${ }^{10}$ Elhorst, Spatial Panel Data Models; LeSage, Applied Econometrics Using MATLAB; Anselin et al. 2006
} 
likelihood procedure outlined in Anselin (1988). Note we slightly modify the use of $W$ here in that the rows have been normalized to sum to 1 (i.e. rows have already been multiplied by $\frac{1}{N_{i}}$ ). The steps of the procedure are as follows:

1. perform OLS for the model: $u=X \beta_{0}+\varepsilon_{0}$

2. perform OLS for the model $W u=X \beta_{L}+\varepsilon_{L}$

3. compute residuals $\varepsilon_{0}=u-X \hat{\beta}_{0}$ and $\varepsilon_{L}=W u-X \hat{\beta}_{L}$

4. given $\varepsilon_{0}$ and $\varepsilon_{L}$, find $\rho$ that maximizes the concentrated likelihood function:

$$
L_{c}=-(n / 2) \ln (\pi)-(n / 2) \ln (1 / n)\left(\varepsilon_{0}-\rho \varepsilon_{L}\right)^{\prime}\left(\varepsilon_{0}-\rho \varepsilon_{L}\right)+\ln |I-\rho W|
$$

5. given $\hat{\rho}$ that maximizes $L_{c}$, compute $\hat{\beta}=\left(\hat{\beta}_{0}-\rho \hat{\beta}_{L}\right)$ and

$$
\hat{\sigma}_{\varepsilon}^{2}=(1 / \eta)\left(\varepsilon_{0}-\rho \varepsilon_{L}\right)^{\prime}\left(\varepsilon_{0}-\rho \varepsilon_{L}\right)
$$

which provides an unbiased estimate of the spatial autoregressive coefficient $\rho$.

\section{B Zillow Data}

We use a monthly time series of county level housing data from the Zillow Home Value Index time series which runs from April 1996 through November 2011. The index seeks to provide an unbiased estimate of the monthly median level home value by county. ${ }^{11}$ Excluding Hawaii and Alaska, the final dataset provided by Zillow includes complete time series for 623 counties and partial time series for an additional 16 counties. The 639 counties included in the index were admitted based on a rubric of five criteria including sparseness of data and unreasonable temporal volatility. ${ }^{12}$

\footnotetext{
${ }^{11}$ Additional information on how the index is created is provided on the Zillow Research site and can be found at http://www.zillow.com/blog/research/2012/01/21/zillow-home-value-index-methodology

${ }^{12}$ A complete list of the criteria for inclusion can be found at http://www.zillow.com/blog/research/2012/01/21/zillowhome-value-index-methodology
} 


\section{References}

Blanchard, O. J. and L. Katz (1992), "Regional evolutions." Brookings Papers on Economic Activity, 1, 1-75.

Burgess, S.M. and S. Profit (2001), "Externalities in the matching of workers and firms in britain." Labour Economics, 8, 313-333.

Campbell, J., S. Giglio, and P. Pathak (2011), "Forced sales and house prices." American Economic Review, 101, 2108-31.

Conley, T. G. and G. Topa (2002), "Socio-economic distance and spatial patterns in unemployment." Journal of Applied Econometrics, 17, 303-327.

Davis, M., J. Fisher, and M. Veracierto (2010), "The role of housing in labor reallocation." Technical report, Federal Reserve Bank of Chicago Working paper, 2010-18.

Desmet, K. and E. Rossi-Hansberg (2010), "On spatial dynamics." Journal of Regional Science, $50,43-63$.

Desmet, K. and E. Rossi-Hansberg (2011), "Spatial development." Working paper, Princeton University.

Egwuekwe, L. (2011), "The geography of the recession." http://www . latoyaegwuekwe.com/geographyofarecession.html.

Elhorst, J. P. (2009), "Spatial panel data models." In Handbook of applied spatial analysis (M. M. Fisher and A Getis, eds.), Springer, Berlin.

Fogli, A. and L. Veldkamp (2011), "Nature or nurture nature or nurture? learning and the geography of female labor force participation." Econometrica, 79, 1103-1138.

Greenstone, M., Rick Hornbeck, and Enrico Moretti (2010), "Identifying agglomeration spillovers: Evidence from winners and losers of large plant openings." Journal of Political Economy, 118, 1103-1138.

Hamilton, J. D. and M. T. Owyang (2012), "The propagation of regional recessions." Review of Economics and Statistics, Forthcoming.

LeSage, J. (1999), The Theory and Practice of Spatial Econometrics. University of Toledo. 
Martin, P., Mayer, and Mayneris F. (2011), "Spatial concentration and plant-level productivity in france." Journal of Urban Economics, 69, 182195.

Mian, A, K. Rao, and A. Sufi (2011), "Household balance sheets, consumption, and the economic slump." Chicago Booth Working Paper, November.

Mian, A. and A. Sufi (2010), "Household leverage and the recession of 2007 to 2009." IMF Economic Review, 58, 74-117.

Molho, I. (1995), "Spatial autocorrelation in british unemployment." Journal of Regional Science, $35,641-658$.

Niebuhr, A. (2003), "Spatial interactions and regional unemployment in europe." European Journal of Spatial Development, 5, 1-26.

Overman, H. and D. Puga (2002), "Unemployment clusters across european regions and countries." Economic Policy, 34, 115-147.

Patacchini, E. and Y. Zenou (2007), "Spatial dependence in local unemployment rates." Journal of Economic Geography, 7, 169-191.

Petrongolo, B. and E. Wasmer (1999), "Job matching and regional spillovers in britain and france." In Developments Recents en Economie Spatiale: Emploi, Concurrence Spatiale et Dynamiques Regionales, Paris: (M. Catin, J-Y. Lesueur, and Y. Zenou, eds.), 39-54, Economica.

Philippon, T. (2003), "An explanation for the joint evolution of firm and aggregate volatility." Working paper, New York University.

Shea, J. (1996), "Comovement in cities." Carnegie Rochester Conference on Public Policy, 7, 169206.

Van Nieuwerburgh, S. and P. O. Weill (2010), "Why has house price dispersion gone up?" Review of Economic Studies, 77, 1567-1606. 